\title{
Competing Risks Copula Models for Unemployment Duration An Application to a German Hartz Reform
}

\author{
Lo, Simon M. S. ; Stephan, Gesine; Wilke, Ralf
}

Document Version

Accepted author manuscript

Published in:

Journal of Econometric Methods

DOI:

10.1515/jem-2015-0005

Publication date:

2017

License

Unspecified

Citation for published version (APA):

Lo, S. M. S., Stephan, G., \& Wilke, R. (2017). Competing Risks Copula Models for Unemployment Duration: An Application to a German Hartz Reform . Journal of Econometric Methods, 6(1). https://doi.org/10.1515/jem-20150005

Link to publication in CBS Research Portal

\section{General rights}

Copyright and moral rights for the publications made accessible in the public portal are retained by the authors and/or other copyright owners and it is a condition of accessing publications that users recognise and abide by the legal requirements associated with these rights.

Take down policy

If you believe that this document breaches copyright please contact us (research.lib@cbs.dk) providing details, and we will remove access to the work immediately and investigate your claim. 


\section{Competing Risks Copula Models for Unemployment Duration: An Application to a German Hartz Reform}

\section{Simon M. S. Lo, Gesine Stephan, and Ralf Wilke}

Journal article (Accepted version)

CITE: Competing Risks Copula Models for Unemployment Duration : An Application to a German Hartz Reform . / Lo, Simon M. S. ; Stephan, Gesine; Wilke, Ralf. In: Journal of Econometric Methods, Vol. 6, No. 1, 01.2017.

DOl: 10.1515/jem-2015-0005

Uploaded to Research@CBS: January २०18 


\title{
Competing risks copula models for unemployment duration: An application to a German Hartz reform*
}

\author{
Simon M.S. Lo ${ }^{\dagger}$ Gesine Stephan $\ddagger$ Ralf A. Wilke ${ }^{\S}$
}

September 2015

Keywords: Archimedean copula, frailty, policy evaluation

\section{JEL: C34, C41, J64}

\begin{abstract}
The copula graphic estimator (CGE) for competing risks models has received little attention in empirical research, despite having been developed into a comprehensive research method. In this paper, we bridge the gap between theoretical developments and applied research by considering a general class of competing risks copula models, which nests popular models such as the Cox proportional hazards model, the semiparametric multivariate mixed proportional hazards model (MMPHM), and the CGE as special cases. Analyzing the effects of a German Hartz reform on unemployment duration, we illustrate that the CGE imposes fewer restrictions on partial covariate effects than standard methods do. Differences are less evident when a more flexible difference-in-differences estimator is applied. It is also found that the MMPHM estimates react more strongly to the choice of the copula than the CGE in terms of the shape of the treatment effect function over time. Thus, the MMPHM produces less robust results in our application.
\end{abstract}

*An earlier version of this paper has been entitled "Estimating the latent effect of unemployment benefits on unemployment duration". We thank the participants at various seminars and conferences for their comments.

†Lingnan University, Rm 218, Ho Sin Hang Building, Lingnan University, Hong Kong, E-mail: simonlo@ln.edu.hk .

${ }^{\ddagger}$ Institute for Employment Research (IAB) and Friedrich-Alexander-Universitaet Erlangen Nuernberg (FAU), Regensburger Str. 104, 90478 Nuremberg, Germany, E-mail: gesine.stephan@iab.de

${ }^{\S}$ Copenhagen Business School, Department of Economics, Porcelaenshaven 16A, 2000 Frederiksberg, Denmark, E-mail: rw.eco@cbs.dk 


\section{Introduction}

The competing risks copula model can be interpreted as a general class of multivariate mixture models (Joe, 1997; Lindsay, 1995), in which the latent transition (or failure) times to different risks are interdependent through an unobserved individual frailty. In these models, marginal survival distributions of latent transition times are jointly modelled by an Archimedean copula. Different families of Archimedean copulas allow for different types of dependencies between marginal survival distributions. Specifying the copula function is equivalent to making assumptions about the frailty distribution, because of a one-to-one correspondence. We investigate whether the copula choice is relevant for empirical result patterns.

The competing risks copula model nests various more specific competing risks models. In this study we focus on two of them. When the latent marginal survival distributions are characterised by proportional hazard functions with nonparametric or piecewise linear baseline hazard, the model can be reduced to a semiparametric Multivariate Mixed Proportional Hazard model (MMPHM) with a parametric Archimedean copula, see e.g. Han and Hausman (1990) and Meyer (1990). When competing risks are independent, the MMPHM reduces to the well-known Cox proportional hazards model. An attractive feature of the MMPHM is that the parameter(s) of the copula function, which determine the degree of dependency, are identified and therefore do not need to be assumed. In empirical research, these models are extremely popular (see van den Berg, 2001, for a review and references).

Another - but much less known - nested model is the Copula Graphic Estimator (CGE) with an Archimedean copula. The CGE was originally suggested by Zheng and Klein (1995) for more general families of copulas. Assuming an Archimedean copula, however, allows for closed form solutions and extensions to multiple risks. Instead of directly specifying the latent marginal survival distributions, the CGE exploits the fact that each latent marginal survival distribution is a function of all risk-specific cumulative incidence functions (CIF). This approach requires knowledge about the copula function and its parameter(s). A number of parametric and semiparametric models for the CIF have been developed. In our application, we will use the semiparametric model suggested by Fine and Gray (1999). This model is characterised by a similar degree of flexibility as the semiparametric MMPHM or the Cox model. One advantage of the CGE is its relative flexibility in modelling the latent marginal survival distributions. We 
derive partial covariate effects on latent survival functions and show that the CGE indeed imposes fewer restrictions on covariate effects than the proportional hazards or constant hazard ratios assumption made in the MMPHM and the Cox model. In particular, it allows the direction of covariate effects to vary with duration. This means for instance that particular characteristics are allowed to increase latent durations in the short run, but decrease them in the longer run.

Our study presents the first direct comparison of the MMPHM and the CGE within a fullyfledged application. We provide empirical evidence for MMPHM estimates being less robust with respect to the choice of the copula function than the CGE. This suggests that presuming the wrong copula - and therefore misspecifying the mixing frailty distribution - induces a larger bias in the MMPHM than in the CGE. Specifically, the shape of the treatment effect function over time is more sensitive to the choice of the copula function for the MMPHM than the CGE. These results are in line with previous findings, which were discussed separately in the literature dealing with the MMPHM (Hausman and Woutersen, 2014a) and the CGE (Zheng and Klein, 1995; Lo and Wilke, 2014). We also find that the estimation of the CGE is less prone to numerical convergence issues than the estimation of the MMPHM. This could be due to the fact that the semiparametric CIF of each risk is estimated separately, which are then utilized by the CGE to compute latent marginal survival distribution. In contrast, the MMPHM jointly estimates all marginal survival distributions of latent risks, which is numerically more challenging.

In our application, we use the MMPHM, the Cox model and the CGE to analyze extensive unemployment duration data. In particular, we present first insights on the effects of an important element of the widely regarded labour market policy changes in Germany - the so-called Hartzreforms - on the risks of different exit routes out of unemployment. The Hartz-reforms are a series of legislative labour market reforms that took place during the first half of the 2000s and were enacted to reshape the poorly performing labour market. We focus on the estimation of the effect of a large scale reduction in the maximum entitlement length for unemployment benefit on unemployment duration in the year 2006. The effect of unemployment benefits on unemployment duration is a major area of interest within the field of economics and social sciences. It has been the topic of numerous substantial theoretical (e.g. Mortensen, 1977, and van den Berg, 1990) and empirical studies (e.g. van Ours and Vodopivec, 2006, and Schmieder et al., 2012). We exploit the natural experiment design of this part of the Hartz-reforms, and apply a difference-in-differences (DID) estimator to estimate the reform effect on the latent marginal distributions of five different 
competing exit risks to leave unemployment.

While we present the first empirical study about the effect of this part of the Hartz-reforms, we have also access to more comprehensive linked register data than related empirical research on previous reforms of the German unemployment benefits. Lee and Wilke (2009) and Arntz et al.(2014) analyse policy changes of the 1980s and 1990s, respectively, but their data do not comprise information on training measures, subsidized self-employment and job search. Other related papers on the effects of entitlement lengths that use similar data - such as Schmieder et al. (2012) and Caliendo et al. (2013) - do not adopt a competing risks framework. We show in our application that exploiting the richness of the data by distinguishing between several risks allows for a more differentiated evaluation of the reform effects.

\section{Political Background and Data}

In this section we describe the basic features of the German unemployment compensation system and of the 2006 reform of unemployment benefit entitlement lengths as well as the data used.

\subsection{Institutional Background}

The German unemployment compensation system consists of contribution based unemployment benefits and tax funded basic income support for needy unemployed. Unemployment benefits are financed mainly through unemployment insurance contributions of workers and firms (experience rating does not apply). The replacement rate amounts to 60-67 percent of the previous wage (dependent on whether there are dependent children in the household or not), while the duration varies with the employment history of workers. After the exhaustion of unemployment benefit entitlements, needy unemployed job seekers are entitled to basic income support, the level of which does not depend on former earnings (since 2005).

A fundamental shortening of maximum unemployment benefit entitlement lengths - announced already during 2003 - took place in February 2006 as part of the so called German Hartz reforms (see Table 1). While the reform affected all workers of age 45 and older, the reduction was larger for older age groups. The decrease in unemployment compensation at expiration of unemployment benefits mainly affects high pre-unemployment earners. In contrast, the compensation level of low earners, who are often entitled for means tested basic income support, are not expected to be 
strongly affected by the reform. We therefore focus the presentation of our results on the non-low pre-unemployment earners, defined as whose last wage rate amounted to higher than two third of the median wage. This is a commonly used definition of non low-wages (see for instance BA Statistik 2010). We have also done the analysis for the low income group. As expected, we did not find sizable effects of the reform.

The 2006 reform was a well-defined natural experiment as it affected particular age groups only. Dlugosz et al. (2014) analyze changes in unemployment inflows in response to the same reform and find evidence for a decrease for workers age 52 and older. They also observe anticipation effects of the reform in the three months ahead of the policy change (11/2005 to 1/2006) for all affected age groups. Although these effects were rather small for persons in the age range 45-51, they were quite large for workers aged 52 and older, with an increase in the transition rate into unemployment by at least (dependent on the age group) one half. The results of Dlugosz et al. (2014) therefore suggest that the composition of unemployed has changed in response to the reform in particular for the aged 52 and older. In consequence, we focus on the age group 45-46. This group had the smallest anticipation effect and there was no systematic decrease in unemployment inflows after the reform. In order to eliminate anticipation effects, we exclude inflows from the period 10/2005 to 2/2006 from our analysis.

For completeness, we add a few institutional details that should, however, have no impact on our results: First, a fundamental reshaping of the German basic income support system was enacted at the beginning of the year 2005. As our analysis restricts itself to entries into unemployment with at least one year entitlement length since the year 2004, all individuals in our sample were affected by this. Second, two previous self-employment subsidy variants were merged into a single one in August 2006. In contrast to the old variants, the new instrument required a remaining unemployment benefit claim of at least 90 days. This affected, however, the treatment and the comparison group likewise. Third, the German government re-extended benefit entitlement lengths to up to 24 months again in the year 2008. This occurred, however, after the end of our observation period.

Insert Table 1 about here. 


\section{$2.2 \quad$ Data}

We use a 25-percent-sample of the Integrated Employment Biographies of the Institute for Employment Research (IAB). These individual data are drawn from several linked administrative sources and contain daily spell information about employment periods subject to social security contributions, job seeking periods, participation in active labour market programs, and unemployment benefit and unemployment assistance claim periods. Our version of the data is right censored at the end of 2008.

The sample used consists of unemployment inflows taking up unemployment benefit receipt between January 2004 and December 2007. We except the period 10/2005 to 2/2006 for the reasons mentioned above. The period 2004-2005 comprise the pre-reform period, while we denote the period 2006-2007 as the post-reform (inflow) period. For the reasons already provided, we compare the age groups 40-44 (control group) and 45-46 (treatment group). As has been mentioned above, we focus on (previous to unemployment) non-low earners, who earned more than two third of the median wage in their last job. Furthermore, we restrict our sample to unemployed who would have had the maximum entitlement length for unemployment benefits under pre-reform regulations. This ensures the comparability of the pre-reform and post-reform sample. We focus on the group of male unemployed with full-time employment before unemployment. Because special regulations apply to seasonal unemployment in the construction sector, we exclude workers, whose last job was located in this sector. While our choice of narrow age groups ensure a clean design to identify the treatment effects, it should be noted that it also reduces the external validity of the empirical findings.

The data provide information on employment periods subject to social security contributions and contact periods with the German Federal Employment Agency. They do not contain information if an individual is unemployed but not registering at the employment agency, has (temporarily) withdrawn from the labour market, has life-time tenure as a civil servant, or is self-employed without being subsidized. For the following analysis, we define an unemployment spell as a sequence of spells of registered unemployment, unemployment benefit receipt, or participation in an active labour market program (with the exception of subsidized employment or self-employment or a long training program of at least 3 months), without any gap of more than a month.

We censor all unemployment spells at 720 days, as this is well beyond the treatment period 
between 365 and 550 days. We therefore only have independent censoring in our data. Our sample consists of 44,465 observations (see Table 2). The number of multiple spells is low in our sample: Within the four strata that we use for estimation (by age and treatment period), we have only 122 individuals with two observations, and none with three observations. There are 1,632 individuals with two spells and 16 individuals with three spells if we were pooling the four strata. Thus, it is likely that a single spell model produces very similar results as a multiple spell model in this application.

We perform competing risks analyses that allow the policy reform under investigation to affect destination states differently. We distinguish between exit states that are more or less desirable from the viewpoint of society. This is important as the consequences of an unemployment reform cannot be solely assessed on the grounds of a reduction in overall unemployment duration. In particular, we consider five states: recall to the previous employer, low-wage full-time employment, other full-time employment (non-low-wage), subsidized self-employment, and other or unknown states. Other states includes entry into part-time employment, into the secondary labour market, or into long training. Unknown states are exits from unemployment, where the data provide no information on the subsequent labor market histories of individuals. The last risk is thus a pooled risk and therefore it does not have a direct interpretation. We presume that non-low wage full-time employment including recall to the non-low wage job are generally desirable exit states, while subsidized self-employment and other or unknown states are less desirable as in most cases the individual still claims some benefits or subsidies or is economically inactive. Transitions into low-wage employment are also considered to be less desirable if an individual received a higher wage before entering unemployment, as the wage cut would indicate a loss in job quality.

Table 2 describes the distribution of destination states in our sample. There are around 10 percent recalls and entries into low-wage jobs at another employer, while around 40 percent enter a new non-low-wage job. Around 15 percent take up subsidized self-employment and around 20 percent exit into an unknown or other state. Of those exiting into an unknown or other state, entry into an unknown state turned out to be most important option.

Insert Table 2 about here. 
In our empirical analysis we employ a regression model to control for a number of observable variables which affect the duration of unemployment. These include socio-demographic characteristics (married, education, nationality), labour market history (since the 1990s), characteristics of the last job (wage, status, sector affiliation, firm size), and regional characteristics (federal state). In order to eliminate inconsistencies in the education and the nationality variable, we apply imputation rules suggested by Fitzenberger et al. (2006). Table 3 in the Appendix presents the descriptive statistics for the regressors. Table 4 in the Appendix describes the sample by destination state.

\section{Competing Risks Copula Models}

We consider a competing risks unemployment duration model with risks $j=1, \ldots, 5$, which are outlined in Section 2.2. $T_{j} \in \mathbb{R}_{+}$is a random variable and denotes the latent duration until a transition to risk $j$ would take place. $C \in \mathbb{R}_{+}$is the independent censoring time. Let $\delta_{j}=1$ if $j=\operatorname{argmin}_{q}\left\{T_{q}\right\}$ and zero otherwise and $T=\min _{q}\left\{T_{q}\right\}$. Let $X=\min (T, C)$ and $\epsilon=1$ if $T \leq C$ and zero otherwise.

Due to the design of the policy reform under investigation, we apply a difference-in-differences (DiD) approach for the identification of reform effects. Let $\boldsymbol{z} \in \mathbb{R}^{K}$ be a $K$-row vector of observable covariates. In particular, $\boldsymbol{z}=\left(\boldsymbol{w}^{\prime}, P, G\right)^{\prime}$, with $P$ as the post reform period dummy variable and $G$ as the treatment group dummy variable. $\boldsymbol{w}$ is a vector of other control variables, which are listed in Tables 3 and 4 . Estimates are based on a random sample of $i=1, \ldots, n$ observations of $\left(X_{i}, \epsilon_{i}, \delta_{1 i}, \ldots, \delta_{5 i}, \mathbf{z}_{i}\right)$. In addition to observables, let $\nu \in \mathbb{R}$ be an unobserved individual frailty term with distribution $G(\nu)$ and is independent of $\boldsymbol{z}$. Assuming a single frailty term could be an important restriction in an application, where the frailty term is risk specific.

Then, let $S_{j}(t \mid \boldsymbol{z}, \nu)=\operatorname{Pr}\left(T_{j}>t \mid \boldsymbol{z}, \nu\right)$ be the latent marginal survival function of $T_{j}$, conditional on observables and unobservables. The cumulative incidence function (CIF) for risk $j$ is $Q_{j}(t \mid \boldsymbol{z})=\operatorname{Pr}\left(T \leq t, \delta_{j}=1 \mid \boldsymbol{z}\right)$. In what follows, we consider a general class of multivariate mixture models (Joe, 1997; Lindsay, 1995), where we have $S_{j}(t \mid \boldsymbol{z}, \nu)=\exp \left(-\nu \Lambda_{j}(t \mid \boldsymbol{z})\right)$ with $\Lambda_{j}(t \mid \boldsymbol{z})=\int_{0}^{t} \lim _{\Delta s \rightarrow 0^{+}} \operatorname{Pr}\left(T_{j} \in[s, s+\Delta s)\left|T_{j} \geq s\right| \boldsymbol{z}\right) / \Delta s d s$ as the cumulative integrated hazard function of risk $j$. Let $S\left(t_{1}, \ldots, t_{5} \mid \boldsymbol{z}, \nu\right)=\operatorname{Pr}\left(T_{1}>t_{1}, \ldots, T_{5}>t_{5} \mid \boldsymbol{z}, \nu\right)$ be the conditional joint survival distribution. Whenever $t_{j}=t$ for all $j$, we write $S(t \mid \boldsymbol{z}, \nu)=\operatorname{Pr}\left(T_{1}>t, \ldots, T_{5}>\right.$ 
$t \mid \boldsymbol{z}, \nu)$, which is the overall survival function. Assuming independence of $T_{j}$ given $(\boldsymbol{z}, \nu)$, we have $S\left(t_{1}, \ldots, t_{5} \mid \boldsymbol{z}, \nu\right)=\prod_{j} S_{j}\left(t_{j} \mid \boldsymbol{z}, \nu\right)=\exp \left(-\nu \sum_{j=1}^{5} \Lambda_{j}\left(t_{j} \mid \boldsymbol{z}\right)\right)$. Then, $S_{j}(t \mid \boldsymbol{z})=\operatorname{Pr}\left(T_{j}>t \mid \boldsymbol{z}\right)$ is obtained by integrating out the frailty distribution, i.e.

$$
S_{j}(t \mid \boldsymbol{z})=\int_{\nu} \exp \left(-\nu \Lambda_{j}(t \mid \boldsymbol{z})\right) d G(\nu)=\mathcal{L}_{\nu}\left(\Lambda_{j}(t \mid \boldsymbol{z})\right)
$$

where $\mathcal{L}_{\nu}$ is the Laplace transform of $G(\nu)$. Similarly, $S\left(t_{1}, \ldots, t_{5} \mid \boldsymbol{z}\right)=\operatorname{Pr}\left(T_{1}>t_{1}, \ldots, T_{5}>t_{5} \mid \boldsymbol{z}\right)$ is obtained by integrating out the frailty distribution, i.e.

$$
S\left(t_{1}, \ldots, t_{5} \mid \boldsymbol{z}\right)=\int_{\nu} \exp \left(-\nu \sum_{j=1}^{5} \Lambda_{j}\left(t_{j} \mid \boldsymbol{z}\right)\right) d G(\nu)=\mathcal{L}_{\nu}\left(\sum_{j=1}^{5} \Lambda_{j}\left(t_{j} \mid \boldsymbol{z}\right)\right)
$$

\subsection{General Copula Model}

The model in (2) can be written in terms of a copula model by setting $\mathcal{L}_{\nu} \equiv \phi_{\theta}^{-1}$, where $\phi_{\theta}^{-1}$ is the inverse of an Archimedean copula generator $\phi_{\theta} . \phi_{\theta}$ is a strictly decreasing function from $[0,1]$ to $[0, \infty]$ such that $\phi(0)=\infty$ and $\phi(1)=0$ with its inverse $\phi_{\theta}^{-1}$ exists. $\theta$, whose support varies with different copula functions (some examples are provided below) is the parameter of the copula generator, which is related to the Kendall's $\tau$ (a general measure of the degree of dependence with range $\tau \in[-1,1])$ by $\tau=4 E\left(\phi_{\theta}^{-1}\left(\sum_{j=1}^{J} \phi_{\theta}\left(S_{j}\right)\right)\right)$ - 1 . In a copula model with $J$ risks, $\phi_{\theta}^{-1}$ is $J$ monotonic on $[0, \infty]$ which implies some restrictions on the support of $\theta$ and thus $\tau$ as well.

Thus, there is a one-to-one relationship between the frailty distribution $G(\nu)$ and the copula generator $\phi_{\theta}$, and (1) can be written as

$$
S_{j}(t \mid \boldsymbol{z})=\phi_{\theta}^{-1}\left(\Lambda_{j}(t \mid \boldsymbol{z})\right)
$$

Combining (2) and (3), (2) provides an Archimedean copula model (Nelsen, 2006), in which the copula links all marginal survival distributions to form a joint distribution:

$$
S\left(t_{1}, \ldots, t_{5} \mid \boldsymbol{z}\right)=\mathcal{L}_{\nu}\left(\sum_{j=1}^{5} \mathcal{L}_{\nu}^{-1}\left(S_{j}\left(t_{j} \mid \boldsymbol{z}\right)\right)\right)=\phi_{\theta}^{-1}\left(\sum_{j=1}^{5} \phi_{\theta}\left(S_{j}\left(t_{j} \mid \boldsymbol{z}\right)\right)\right) .
$$

In our application, we use the Frank and Clayton copulas for reasons given below. They have the following properties (for more details on copulas see for example Nelsen, 2006):

- The Clayton copula, characterised by $\phi_{\theta}(s)=\left(s^{-\theta}-1\right) \theta$, corresponds to a Gamma frailty distribution with $\tau=\theta /(2+\theta)$ and $\theta \in[-1, \infty\} \backslash\{0\}$; 
- The Frank copula with $\phi_{\theta}(s)=-\ln ((\exp (-\theta s)-1) /(\exp (-\theta)-1))$ corresponds to a discrete frailty distribution related to a logarithmic random variable. $\tau$ and $\theta$ are related by $(\mathcal{D}(\theta)-$ 1) $/ \theta=(1-\tau) / 4$, where $\mathcal{D}$ is the Debye function. $\theta \in \mathbb{R} \backslash\{0\}$. See also Joe (2015).

For convenience, we use the notation $\phi_{\tau}$ in place of $\phi_{\theta}$ in what follows, as $\tau$ can be readily interpreted as the degree of dependency irrespective of the type of copula function. In our model with five competing risks, the requirement that $\phi_{\tau}^{-1}$ needs to be 5 -monotonic imposes further restrictions on the support of $\theta$ and thus the set of possible Kendall's $\tau$ as well. In our application, restrictions are given by $\tau \in[-.01,1]$ for the Frank copula and $\tau \in[-.21,1]$ for the Clayton copula (Joe, 1997).

Another approach to characterise different copula generators is by considering their tail dependence. In a two risks model, upper tail dependence is defined as $\chi_{U}=\lim _{s \rightarrow 1^{-}} \operatorname{Pr}\left(T_{1} \leq S_{1}^{-1}(s) \mid T_{2} \leq\right.$ $\left.S_{2}^{-1}(s)\right)$ and lower tail dependence is defined as $\chi_{L}=\lim _{s \rightarrow 0^{+}} \operatorname{Pr}\left(T_{1}>S_{1}^{-1}(s) \mid T_{2}>S_{2}^{-1}(s)\right)$. For a more general presentation see Nelsen (2006). The Frank copula has no tail dependence $\left(\chi_{U}=\chi_{L}=0\right)$, and the Clayton copula has lower tail dependence $\left(\chi_{U} \in(0,1], \chi_{L}=0\right)$. There also exist copulas with upper tail dependence (i.e. Gumbel copula) and with both upper and lower tail dependence (Joe-Clayton copula). We restrict the empirical analysis to copulas without upper tail dependence, in particular the Frank and the Clayton copula, because the estimation of one of our two models (i.e. the mixed proportional hazard model) failed to converge when using a copula with upper tail-dependence.

In what follows, we introduce two modelling approaches for $S_{j}(t \mid \boldsymbol{z})$ in (3): The semiparametric Multivariate Mixed Proportional Hazards Model (MMPHM) and the Copula Graphic Estimator (CGE). The main difference between these approaches is that the former directly models and estimates $S_{j}$, while the latter indirectly determines $S_{j}$ after the CIFs have been modelled and estimated.

\subsection{MMPHM}

This model imposes the functional form

$$
S_{j}^{m}(t \mid \boldsymbol{z})=\phi_{\tau}^{-1}\left(\Lambda_{j 0}(t) \exp \left(\boldsymbol{z} \boldsymbol{\beta}_{j}\right)\right)
$$

with $\Lambda_{j 0}(t)$ as the so-called cumulative baseline hazard. Let $A_{l}$, with $l=0, \ldots, L$, be disjoint intervals on the support of $X$ whose union is $\mathbb{R}_{+}$(or a subset of it). In our empirical study, we 
use a model with piecewise constant $\Lambda_{j 0}(t)=\int_{t} \sum_{l=0}^{L} \alpha_{l} 1\left(s \in A_{l}\right) d s$, where $1\left(t \in A_{l}\right)=1$ if the condition is met and 0 otherwise. In our application we set $L=6$ and the $A_{l}$ 's are different for different risks. Based on simulations, Han and Hausman (1990) show that this approximation to an unknown baseline hazards function does not affect the accuracy of the parameter estimates. In this model, $S_{j}^{m}(t \mid \boldsymbol{z})$ in (1) is identified and can be estimated by maximum likelihood methods. The likelihood function to be maximised is

$$
\ell(\boldsymbol{\beta}, \tau)=\prod_{i=1}^{n} \prod_{j=1}^{5} f_{j}\left(X_{i} \mid \boldsymbol{z}_{i}\right)^{\epsilon_{i} \delta_{j i}} S\left(X_{i} \mid \boldsymbol{z}_{i}\right)^{\left(1-\epsilon_{i}\right)},
$$

where

$$
\begin{aligned}
f_{j}(t \mid \boldsymbol{z}) & =-\partial S\left(t_{1}, \ldots, t_{5} \mid \boldsymbol{z}\right) /\left.\partial t_{j}\right|_{t_{1}=\ldots=t_{5}=t} \\
& =\lim _{\Delta t \rightarrow 0^{+}} \operatorname{Pr}\left(T \in[t, t+\Delta t), \delta_{j}=1\right) / \Delta t \\
& =\phi_{\tau}^{-1^{\prime}}\left(\sum_{j=1}^{5} \phi_{\tau}\left(S_{j}^{m}\left(t_{j} \mid \boldsymbol{z}\right)\right)\right) \phi_{\tau}^{\prime}\left(S_{j}^{m}\left(t_{j} \mid \boldsymbol{z}\right)\right) \phi_{\tau}^{-1^{\prime}}\left(\Lambda_{j 0}(t) \exp \left(\boldsymbol{z} \boldsymbol{\beta}_{j}\right)\right) \Lambda_{j 0}^{\prime}(t) \exp \left(\boldsymbol{z} \boldsymbol{\beta}_{j}\right) .
\end{aligned}
$$

The likelihood is maximised in $\boldsymbol{\beta}$ and $\tau$. A special - but well known - case occurs when $\nu$ in (2) is degenerate and equals to one. In this case (3) and (4) constitute the independence copula model with $\phi_{\tau}(s)=\exp (-s)$. The MMPHM then reduces to the Cox proportional hazard model with independent risks:

$$
S_{j}^{o}(t \mid \boldsymbol{z})=\exp \left(-\Lambda_{j 0}(t) \exp \left(\boldsymbol{z} \boldsymbol{\beta}_{j}\right)\right)
$$

\subsection{CGE}

Alternatively, $S_{j}(t \mid \boldsymbol{z})$ in (3) can be indirectly modeled as a function of the copula and cumulative incidence functions. The CGE (Zheng and Klein, 1995) therefore does not impose direct restrictions on the marginal survival distributions. Given the observables, $\tau$, and that the copula is Archimedean we have (Rivest and Wells, 2001)

$$
S_{j}^{c}(t \mid \boldsymbol{z}, \tau)=\phi_{\tau}^{-1}\left[-\int_{0}^{t} \phi_{\tau}^{\prime}\left(1-\sum_{q=1}^{5} Q_{q}(u \mid \boldsymbol{z})\right) Q_{j}^{\prime}(u \mid \boldsymbol{z}) d u\right] .
$$

If $\tau$ is unknown, sensitivity analyses using different values of $\tau$ can be conducted. Once the CIFs are estimated, $S_{j}^{c}(t \mid \boldsymbol{z}, \tau)$ are computed according to (8) for a given $\tau$. As a matter of fact, the estimation and crafting of the CIF does not require knowledge of the copula or $\tau$. To maintain a 
similar degree of flexibility as in the model for the MMPHM, we consider a semiparametric model for the CIF. In particular, we use the model by Fine and Grey (1999) which assumes

$$
Q_{j}(t \mid \boldsymbol{z})=1-\exp \left(-\Lambda_{j 0}^{C I}(t) \exp \left(\boldsymbol{z} \boldsymbol{\gamma}_{j}\right)\right)
$$

with $\Lambda_{j 0}^{C I}(t)$ as an unspecified baseline cumulative subdistribution hazard such that $\Lambda_{j 0}^{C I}(t)=$ $\int_{0}^{t} \lim _{\Delta s \rightarrow 0^{+}} \operatorname{Pr}\left(T \in[s, s+\Delta s), \delta_{j}=1 \mid T \geq s \cup\left(T \leq t \cap \delta_{j} \neq 1\right)\right) / \Delta s d s$. The CIF in (9) can be estimated by maximising the partial likelihood

$$
\ell\left(\boldsymbol{\gamma}_{j}\right)=\prod_{i=1}^{n}\left[\frac{h_{i}\left(X_{i}\right) \exp \left(\boldsymbol{z}_{i} \boldsymbol{\gamma}_{j}\right)}{\sum_{k \in R_{i}} h_{k}\left(X_{i}\right) \exp \left(\boldsymbol{z}_{k} \boldsymbol{\gamma}_{j}\right)}\right]^{\delta_{i} h_{i}\left(X_{i}\right)},
$$

where $h_{i}(t)$ equals to a weighting scheme according to the inverse probability of censoring weighting techniques (Robin and Rotnitzky, 1992), and $R_{i}$ is the risk set defined as $\left\{k:\left(X_{k} \geq X_{i}\right) \cup\left(X_{k} \leq\right.\right.$ $\left.\left.X_{i} \cap \delta_{j} \neq 1 \cap \epsilon=1\right)\right\}$. In contrast to (6), the partial likelihood for each of the risks is maximised separately in (10). As the copula graphic estimator in (8) requires continuity of $Q_{j}(t \mid \boldsymbol{z})$ in $t$, we apply a local polynomial Kernel smoother to the estimates of $\Lambda_{j 0}^{C I}(t)$ in $(9)$.

\subsection{Covariate and Treatment Effects}

In this subsection we discuss covariate effects for the different models and we present the differencein-differences approach for estimation of the treatment effect of the policy change. We show that one advantage of the CGE over the MMPHM is its flexibility in modelling partial covariate effects, i.e. $\partial S_{j}(t \mid \mathbf{z}) / \partial z_{k}$ (For more details on the calculation of the counterfactuals in duration models see Hausman and Woutersen, 2014a). We illustrate this in our application with a continuous regressor $w_{k}$, which will be daily pre-unemployment salary. For the MMPHM, the partial effect of $w_{k}$ on $S_{j}$ in (1) and (5) is

$$
\pi_{j k}^{m}(t \mid \boldsymbol{z})=\frac{\partial S_{j}^{m}(t \mid \boldsymbol{z})}{\partial w_{k}}=\phi_{\tau}^{-1^{\prime}}\left(\Lambda_{j 0}(t) \exp \left(\boldsymbol{z} \boldsymbol{\beta}_{j}\right)\right) \Lambda_{j 0}(t) \exp \left(\boldsymbol{z} \boldsymbol{\beta}_{j}\right) \beta_{j k} .
$$

As $\phi_{\tau}^{-1}(s) \geq 0$ is 5 -monotone, $\phi_{\tau}^{-1^{\prime}}(s) \leq 0$ for all $s \geq 0$, and thus the sign of the covariate effect in (11) is always the opposite of the sign of $\beta_{j k}$ for all values of $t$. Evidently, the same restriction applies to the covariate effect in the Cox proportional hazard model with $\tau=0$ :

$$
\pi_{j k}^{o}(t \mid \boldsymbol{z})=\frac{\partial S_{j}^{o}(t \mid \boldsymbol{z})}{\partial w_{k}}=-\exp \left(\Lambda_{j 0}(t) \exp \left(\boldsymbol{z} \boldsymbol{\beta}_{j}\right)\right) \Lambda_{j 0}(t) \exp \left(\boldsymbol{z} \boldsymbol{\beta}_{j}\right) \beta_{j k}
$$


In contrast, the direction of the partial effect for the CGE using (8) and (9) can vary with $t$ :

$$
\begin{aligned}
\left.\pi_{j k}^{c}(t \mid \boldsymbol{z}), \tau\right)= & \frac{\partial S_{j}^{c}(t \mid \boldsymbol{z}, \tau)}{\partial w_{k}} \\
= & \phi_{\tau}^{-1^{\prime}}\left[-\int_{0}^{t} \phi_{\tau}^{\prime}\left(1-\sum_{q=1}^{5} Q_{q}(u \mid \boldsymbol{z})\right) Q_{j}^{\prime}(u \mid \boldsymbol{z}) d u\right] Q_{j}^{\prime}(t \mid \boldsymbol{z}) \exp \left(\boldsymbol{z} \boldsymbol{\gamma}_{j}\right) \gamma_{j k} \\
& \times \int_{0}^{t} \phi_{\tau}^{\prime}(S(u \mid \boldsymbol{z}))\left(\Lambda_{j 0}^{C I}(u) \exp \left(\boldsymbol{z} \boldsymbol{\gamma}_{j}\right)-1\right) \\
& +\phi_{\tau}^{\prime \prime}(S(u \mid \boldsymbol{z})) \sum_{q=1}^{5}\left[\left(1-Q_{q}(u \mid \boldsymbol{z})\right) \Lambda_{q 0}^{C I}(u) \exp \left(\boldsymbol{z} \boldsymbol{\gamma}_{q}\right) \gamma_{q k}\right] d u
\end{aligned}
$$

Thus, the CGE appears to impose fewer restrictions on the shape of partial effects than the MMPHM. We will illustrate in our application that the different models indeed produce different sets of results.

The treatment effect of the policy reform is determined by computing the difference-in-differences between the latent marginal distributions of four sub-samples stratified by $P$ and $G$. The DID reform effect at duration $t$ for the MMPHM, the Cox model, and the CGE is modelled as:

$$
\begin{aligned}
\Delta_{j}^{m}(t \mid \boldsymbol{w}) & =-\left(S_{j}^{m}\left(t \mid \boldsymbol{z}_{11}\right)-S_{j}^{m}\left(t \mid \boldsymbol{z}_{10}\right)-S_{j}^{m}\left(t \mid \boldsymbol{z}_{01}\right)+S_{j}^{m}\left(t \mid \boldsymbol{z}_{00}\right)\right) ; \\
\Delta_{j}^{o}(t \mid \boldsymbol{w}) & =-\left(S_{j}^{o}\left(t \mid \boldsymbol{z}_{11}\right)-S_{j}^{o}\left(t \mid \boldsymbol{z}_{10}\right)-S_{j}^{o}\left(t \mid \boldsymbol{z}_{01}\right)+S_{j}^{o}\left(t \mid \boldsymbol{z}_{00}\right)\right) \\
\Delta_{j}^{c}(t \mid \boldsymbol{w}, \boldsymbol{\tau}) & =-\left(S_{j}^{c}\left(t \mid \boldsymbol{z}_{11}, \tau_{11}\right)-S_{j}^{c}\left(t \mid \boldsymbol{z}_{10}, \tau_{10}\right)-S_{j}^{c}\left(t \mid \boldsymbol{z}_{01}, \tau_{01}\right)+S_{j}^{c}\left(t \mid \boldsymbol{z}_{00}, \tau_{00}\right)\right) .
\end{aligned}
$$

where $\boldsymbol{z}_{p g}=(\boldsymbol{w} \mid P=p, G=g)^{\prime}$. By stratifying the sample by $P$ and $G$, the regressors reduce to $\boldsymbol{w}$. This model for the reform effect imposes only mild restrictions provided that in all models the baseline hazard is nonparametric or piecewise linear and can vary freely across the four strata. Our approach is sufficiently flexible that the policy reform may affect $S_{j}$ only in certain intervals of $t$, i.e. the treatment interval, while there may be no effects for other $t$. If we had modelled the DID effect by means of a simple parametric interaction term $P * G$, we would have imposed much stronger restrictions, similar to the above covariate effects. However, this is bought at the expense of splitting up the sample into four strata (treatment and control group for the preand post-reform period). In our application, the population quantities in (14)-(16) are replaced by their sample analogues. As the $S_{j}$ s are estimated separately in the four sub-samples, $\tau$ is also allowed to vary across the strata (except in the Cox model, where $\tau=0$ by definition), i.e. $\boldsymbol{\tau}=\left(\tau_{11}, \tau_{10}, \tau_{01}, \tau_{00}\right)^{\prime}$, where $\tau_{p g}$ equals Kendall's $\tau$ in the stratified sample of $P=p$ and $G=g$. While the MMPHM produces four different estimates for $\tau$, in the CGE these values are to be 
chosen by the researcher. We elaborate the selection of $\tau$ when presenting the results. Stata code for the copula graphic regression estimator can be requested from the first author. We use the bootstrap by sampling the estimation data randomly with replacement to construct confidence intervals.

\section{Empirical Results}

In this section, we present comparative estimation results for the MMPHM, the Cox model as its special case and the CGE. We first consider estimated partial effects, followed by an investigation of the effect of a reduction in the entitlement length for unemployment benefits on unemployment duration using the DiD framework. While the focus of these steps is on differences in estimated effects between methods, we shortly discuss the results of our application with regard to the economics subject matter at the end of this section.

\subsection{Covariate Effects}

For partial covariate effects, we analyse how a marginal increase in the pre-unemployment salary is related with the marginal survival distribution. A higher salary might result from a higher individual productivity (if not adequately controlled for by the other observables). But at the same time a higher salary typically leads to a higher level of unemployment benefits (as their level depends on the salary level in some pre-unemployment period). Thus, it is an empirical exercise, which of the effects dominates.

We compute the marginal effect for the models discussed in Section 3 as given in (11), (12) and (13). Figure 1 shows various estimates obtained by the MMPHM, the Cox model and the CGE by conditioning the sample on the treatment group $(P=1)$ in the post-reform period $(G=1)$. The estimates are evaluated with the other variables at their sample averages, i.e. $\boldsymbol{z}_{11}=\{\overline{\boldsymbol{w}} \mid 1,1\}$. Results for the Frank copula are given in Figure 1(a) and for the Clayton copula in panel (b).

Insert Figure 1 about here.

The estimated degree of dependence varies rather strongly with the choice of the copula. The 
estimated $\tau$ from the MMPHM with Frank copula is 0.03, which explains why the MMPHM and the Cox model produce similar results in this case. For the Clayton copula, the estimated $\tau$ is 0.44 which leads to rather different partial effects for the MMPHM. In particular, their size and sometimes even their sign apparently depend on the choice of the copula. In their influential simulation study Baker and Melino (2000) also observe strongly changing estimated degrees of dependence for a related class of proportional hazard models with unobserved heterogeneity. The CGE is displayed for $\tau=0$ (darkest solid line) , 0.1, .., 0.9 (lightest solid line). Estimated partial effects for the CGE are rather robust with regard to the choice of the copula. They vary to some extent in size (and partly also in sign) when changing $\tau$. But overall the CGE produces a rather robust picture of the estimated partial effects.

Moreover, it is apparent from Figure 1 that the CGE imposes fewer restrictions on the shape of the partial effects. For instance, the partial effects for the MMPHM and the Cox model do not change signs as duration increases, but there are more non-monotonicities and changes in the signs for the CGE based estimates. The direction of the estimated partial effects differs across risks for all models, which suggests a diverse pattern and justifies a competing risks approach.

\subsection{Treatment Effects}

In this subsection we present estimates for the DID reform effect on the latent marginal survival functions using the MMPHM, Cox and the CGE as defined by (14), (15) and (16). We present estimation results for an average individual in the sample, i.e. $\overline{\boldsymbol{w}}$. We first focus on the CGE with Frank copula and consider the special case when $\tau$ is the same in all four strata.

Figure 2 shows the estimated reform effects with $\tau=0$ (darkest solid line) , 0.1, .., 0.9 (lightest solid line). The estimates clearly suggest the presence of a negative treatment effect on latent survival probabilities for all risks: Latent survival probabilities decreased after shortening the maximum length of unemployment benefit entitlements. The maximum of the treatment effect arises at about day 400, which is around one month after the start of the treatment period (days 366-550). Towards the end of the treatment period, estimated effects return to zero. The shape of estimated effects is rather robust with respect to the choice of $\tau$. For some risks, the size of the effect is also robust but for others (such as recall) it changes strongly with $\tau$. For all risks, the size of estimated reform effect is smallest when $\tau=0$. This suggests that assuming independence between competing risks will lead to underestimation of the size of effects if the true $\tau$ does not 
equal zero. Figure 2 therefore provides evidence that the reduction in benefit entitlements have led to a shortening in latent durations. Depending on the assumed copula parameter and risk these changes can be sizable and amount up to $10-15 \%$ points. As next steps we check whether these changes are statistically significant and whether similar results are being obtained with MMPHM and Cox.

Insert Figure 2 about here.

To illustrate the role of random sampling errors for these estimates we report bootstrap confidence intervals for the estimates with $\tau=\{0,0.5,0.9\}$ in Figure 3. It is apparent that estimates are significant in parts of the treatment period for all risks (except for recall) and for all $\tau$. Compared with the sensitivity analysis presented in Figure 2, the uncertainty due to random sampling plays a similar role as the uncertainty of not knowing $\tau$. The former, however, disappears when the sample increases while the latter is a feature of the population model (and does not disappear as the number of observations increases).

Insert Figure 3 about here.

We now turn to a comparison of the CGE with the MMPHM and the Cox model. Figure 4(a) shows the estimated reform effects for the MMPHM with Frank copula, where $\hat{\tau}_{00}=0.00$, $\hat{\tau}_{01}=0.03, \hat{\tau}_{10}=0.01, \hat{\tau}_{11}=0.03$. In addition, Figure $4(\mathrm{a})$ also shows the CGE estimated with the estimated $\tau \mathrm{s}$ of the MMPHM. It is evident that both estimates are rather similar, producing the same direction and almost the same size of the estimated reform effect on survival probabilities. A comparison with the results of the Cox model is given in Figure 4(b). The CGE results are obtained under the equivalent assumption that $\tau=0$, and it is apparent that the CGE and the Cox point estimates are rather similar in shape. The Cox model estimates tend to be larger in size around the peak of the effects. Thus, we obtain evidence that choosing a more flexible specification of the DiD reform effect - based on four stratified estimates - leads to rather robust result pattern across statistical models. Moreover, using stratified estimates the estimated reform 
effect can vary in size and direction across $t$ for all models, lifting important restrictions on partial covariate effects in the MMPHM and the Cox model.

Insert Figure 4 about here.

Figure 5 shows bootstrap confidence intervals for the point estimates in Figure 4. It is apparent that the confidence intervals for the MMPHM based estimates are wider than for the CGE, while the Cox model based estimates and the CGE estimates have similarly sized confidence bands. This could be partially explained by the fact that the MMPHM estimates $\tau$, while the CGE and Cox model presume it. Assuming $\tau$ imposes more structure on the model and therefore reduces the sampling error in the CGE and Cox model. Figure 5(c) shows that the confidence intervals for the MMPHM reduce considerably when the values of $\tau$ are considered to be given; but confidence intervals are still generally wider than those for the CGE. This suggests that the CGE tends to produce more precise estimates. As shown in Figure 3, the CGE produces significant estimates of the reform effect for all $\tau$, providing a robust finding. In contrast, the MMPHM estimates for unknown $\tau$ are mainly insignificant and only partly significant for assumed $\tau$.

Insert Figure 5 about here.

Our next robustness check is with regard to the assumed copula. Figure 6 presents estimated reform effects when the Clayton copula is used instead of the Frank copula. Because both the Frank and Clayton copula reduce to the independence copula when $\tau=0$, the results for the Cox model do not change in this regard. Figure 6(a) shows how the results for the MMPHM change with the choice of the copula. It is apparent that the general shape pattern of the estimated effects are rather different in some cases. Particularly, the direction of the effects changes before the start of the treatment period for recall, self-employment and unknown and other. The maximum reform effect shifts rightward to the start of the treatment period (i.e. day 365) for all risks. Moreover, the maximum effect even doubles for some risks. The difference could be partly explained by the rather different estimated values of $\boldsymbol{\tau}$ when the Clayton copula is used. For the Frank copula 
they were estimated to be close to zero but for the Clayton copula they are $\tau_{00}=.46, \tau_{01}=.40$, $\tau_{10}=.51$, and $\tau_{11}=.44$ and thus suggesting a quite strong positive dependence between $S_{j}$ s. It remains unclear which of the two copulas in the MMPHM produce a better estimate of $\boldsymbol{\tau}$. But the log likelihoods suggest that the Clayton copula has better fit than the Frank copula. Specifically, the log likelihoods for the Clayton copula MMPHM are -115171.32, -88144.069, -34977.286, and -26599.277 in the group of $\boldsymbol{z}_{00}, \boldsymbol{z}_{01}, \boldsymbol{z}_{10}$, and $\boldsymbol{z}_{11}$ respectively. Log likelihoods for the Frank copula MMPHM are $-136950.26,-105582.01,-41296.189$, and -31798.445 for the same groups. However, as the Clayton and Frank copula are not nested, no straightforward likelihood ratio test is available to compare these two models. In general, given that we observe strong changes in estimated $\tau \mathrm{s}$ across copulas, we do not recommend pre-estimating $\tau$ with the MMPHM and then assuming it to be the correct value for the CGE. This is only done in this section for the purpose of comparing the CGE and MMPHM.

Figure 6(b) shows how the results for the CGE change with the choice of the copula and by using different $\boldsymbol{\tau}$ s from the respective MMPHM estimates. In contrast to the MMPHM, the patterns and the directions of the estimated effects do not change much; only sizes are larger with the Clayton copula. When comparing the results in panels (a) and (b), it becomes apparent that the MMPHM estimates are more sensitive with respect to the choice of the copula function. The importance of a correct specification of the mixture distribution in the piecewise-constant MMPHM has already been observed by Hausman and Woutersen (2014b). In contrast, the previous literature for the CGE has generally found that the choice of the copula is less relevant than the choice of $\tau$ (Zheng and Klein, 1995; Lo and Wilke, 2014). But it is unclear so far whether and to what extent the CGE is less sensitive to the choice of the copula function than the MMPHM. Here, a direct comparison using the same data confirms previous findings and provides evidence that assuming the wrong copula - and therefore mixture distribution - induces a larger bias in the MMPHM than in the CGE.

Finally, the estimates on the grounds of MMPHM and CGE using the Clayton copula are presented in Figure 6(c). In contrast to Figure 4(a), the sets of estimates using the Clayton copula are not as robust as those based on the Frank copula. But the general patterns of the reform effects are still similar for most of the risks, except that the sizes of the peak of the reform effects are different for the risks low-wage full-time and unknown and other. Moreover, the MMPHM produces implausible positive estimates for the reform effect for risks recall and 
unknown and other at short durations, although these are not statistically significant.

Insert Figure 6 about here.

\subsection{Summary of empirical findings}

We summarize our main findings as follows: Our results for the partial covariate effect of preunemployment earnings on latent marginal survival curves reveal that the MMPHM and the Cox model impose strong restrictions on the shape of time-varying effects. Moreover, the choice of the copula seem to affect quite strongly the estimates for the MMPHM, leading to rather different estimates for $\tau$ and to different patterns for the estimated partial effects. The CGE is more flexible and allows the effect to change its direction across duration. Furthermore, result patterns for the CGE appear to be more robust with respect to the choice of the copula.

With regard to the subject matter, we obtain evidence for negative effects of a higher preunemployment salary on the latent marginal survival curves for three main routes out of unemployment: Taking up a non low-wage full time job, entering subsidized self-employment, and transiting in the pooled remainder state (unknown destination, long training, secondary labour market, part-time work). These effects become more negative over time.

In further steps, we investigated the effects of a fundamental shortening of the maximum unemployment benefit entitlement duration on unemployment duration. We find evidence for a left shift of all latent marginal survival curves (except for recall), which gives some support to the hypothesis that individuals with shorter entitlement lengths have shorter unemployment durations. The peak of estimated treatment effects is at or shortly after the start of the treatment period. This finding is very robust across all methods and models and there is only partly disagreement on the size of the effect.

The largest effects of the reform are found to be for risks that are less desirable from the viewpoint of society: low-wage employment, subsidized self-employment, and exits into unknown and other states. For these risks, the latent survival curves decrease by around 5 to 15 percentage points at their peaks. Moreover, for the risks low-wage and other full-time employment, the estimated effects are already negative after less than half a year of unemployment duration. This 
suggests that the job taking speed has already increased considerably before entitlements are about to expire.

\section{Policy Discussion of the Empirical Findings}

We compare the merits of several copula based competing risks duration models to investigate, whether and to what extent the unemployment compensation system affects the duration of unemployment. Based on comprehensive linked administrative data and exploiting an exogenous variation in entitlements due to an important policy change, our paper presents several interesting observations.

Our results suggest that the effect of unemployment benefits on unemployment duration varies across risks. While related previous research has mainly focused on exits to employment or on exits out of unemployment, we distinguish between five risks, namely recalls, low-wage jobs, nonlow-wage jobs, subsidized self-employment, and other states (encompassing long training, work in the secondary labour market, and labour market withdrawals). Our results suggest that it is important to distinguish between desirable and less desirable destination states.

Latent durations for all risks decrease in response to the reform. Estimated effects are found to be smallest for the more desirable destination states as recalls and non-low-paid full-time employment. Most recall times in our sample occur within a six-months-period only, which might explain that the reform did not affect the timing of recalls. We find a stronger decrease in latent durations for taking up low-paid employment, entering self-employment subsidies or transiting into another state. Comparing with a transition into a job with decent remuneration, this is obviously less desirable for the individual unemployed as well as from a policy perspective.

Regarding subsidised self-employment, we find strong effects at the expiration date of unemployment benefits, i.e. the timing of firm creation is strongly related with the timing of the decrease in benefit levels. This suggests that these subsidies may have been to some extent used as a follow up funding source for the unemployed. Indeed, the institutional setup in Germany had to some extent encouraged free riding, as the eligibility for self-employment subsidies is not means tested and had to be granted by law if the business plan satisfied some minimum standards until 2012. The design of the self-employment subsidies for unemployed in Germany therefore casts some doubts whether all start-ups had occurred in response to a promising business idea. A 
labour market reform in Germany enacted at the beginning of 2012 altered access conditions to subsidized self-employment and made the subsidy much less financially attractive. 


\section{References}

[1] Arntz, M., Lo, S.M.S. and Wilke, R.A. (2014), Bounds Analysis of Competing Risks: A Nonparametric Evaluation of the Effect of Unemployment Benefits on Migration in Germany, Empirical Economics, 46, 199-228.

[2] BA Statistik (2010), Beschäftigungsstatistik: Sozialversicherungspflichtige Arbeitsentgelte, Sonderbericht der Statistik der BA.

[3] Baker, M. and Melino, A. (2000), Duration dependence and nonparametric heterogeneity: A Monte Carlo study, Journal of Econometrics, 96, 357393.

[4] Caliendo, M., Tatsiramos, K. and Uhlendorff, A. (2013), Benefit Duration, Unemployment Duration and Job Match Quality: A Regression Discontinuity Approach Journal of Applied Econometrics, 28, 604-627.

[5] Dlugosz, S., Stephan, G. and Wilke, R.A. (2014), Fixing the leak: Unemployment incidence before and after the 2006 reform of unemployment benefits in Germany, German Economic Review, 15, 329-352.

[6] Fine J.P. and Gray R.J. (1999), A proportional hazards model for the subdistribution of a competing risk, Journal of the American Statistical Association, 94, 496-509.

[7] Fitzenberger, B., Osikominu, A. and Völter, R. (2006), Imputation rules to improve the education variable in the IAB employment subsample, Schmollers Jahrbuch, 126, 405-436.

[8] Han, A. K. and Hausman, J. A. (1990), Flexible Parametric Estimation of Duration and Competing Risk Models, Journal of Applied Econometrics, 5, 1-28.

[9] Hausman, J. A. and Woutersen, T. M. (2014a), Estimating a Semi-Parametric Duration Model without Specifying Heterogeneity, Journal of Econometrics, 178, 114-131.

[10] Hausman, J. A. and Woutersen, T. M. (2014b), Estimating the Derivative Function and Counterfactuals in Duration Models with Heterogeneity, Econometric Reviews, 33, 472-496.

[11] Joe, H. (1997), Multivariate Models and Dependence Concepts. Chapman \& Hall, London, UK. 
[12] Joe, H. (2015), Dependence Modeling with Copulas. CRC Press, Boca, Ration, FL.

[13] Lindsay, B. (1995), Mixture Models: Theory, Geometry and Applications. Institute of Mathematical Statistics, Haywood, California.

[14] Lee, S. and Wilke, R.A. (2009), Reform of Unemployment Compensation in Germany: A nonparametric Bounds Analysis using Register Data, Journal of Business and Economic Statistics, $27,176-192$.

[15] Lo, S.M.S. and Wilke, R.A. (2014), A Regression Model for the Copula Graphic Estimator, Journal of Econometric Methods, 3, 21-46.

[16] Meyer, B. D. (1990), Unemployment Insurance and Unemployment Spells, Econometrica, 58, 757-782.

[17] Mortensen, D.T. (1977), Unemployment Insurance and Job Search Decisions, Industrial and Labor Relations Review, 30, 505-517.

[18] Nelsen, R.B. (2006), An Introduction to Copulas, 2nd Edition, Springer, New York.

[19] Rivest, L. and Wells, M.T. (2001), A Martingale Approach to the Copula-Graphic Estimator for the Survival Function under Dependent Censoring, Journal of Multivariate Analysis, 79, $138-155$.

[20] Robins, J. M. and Rotnitzky, A. (1992), Recovery of information and adjustment for dependent censoring using surrogate markers. AIDS Epidemiology - Methodological Issues, (Edited by N. Jewell, K. Dietz and V. Farewell), 297-331. Birkhäuser, Boston.

[21] Schmieder J.F., von Wachter, T. and Bender, S. (2012), The Effects of Extended Unemployment Insurance over the Business Cycle: Evidence from Regression Discontinuity Estimates Over Twenty Years, Quarterly Journal of Economics, 127, 701-752.

[22] van den Berg, G. (1990), Nonstationarity in Job Search Theory, The Review of Economic Studies, 57, 255-277.

[23] van den Berg, G. (2001), Duration models: specification, identification and multiple durations, Handbook of Econometrics, in: J.J. Heckman \& E.E. Leamer (ed.), Ed 1, Vol 5, 3381-3460. 
[24] van Ours, J.C.. and Vodopivec, M. (2006), How Shortening the Potential Duration of Unemployment Benefits Affects the Duration of Unemployment: Evidence from a Natural Experiment, Journal of Labor Economics, 24, 351-378.

[25] Zheng, M. and Klein, J.P. (1995), Estimates of marginal survival for dependent competing risks based on assumed copula. Biometrika, 82, 127-138. 


\section{Appendix}

\section{Tables}

Table 1: The 2006 reform of unemployment benefit entitlement lengths in Germany.

\begin{tabular}{|c|c|c|c|}
\hline \multirow[b]{2}{*}{ Age } & \multicolumn{3}{|c|}{ Maximum entitlement length in months } \\
\hline & Until 1/2006 & $2 / 2006$ to $12 / 2007$ & Reduction \\
\hline$<45$ & 12 & 12 & 0 \\
\hline $45-46$ & 18 & 12 & 6 \\
\hline $47-51$ & 22 & 12 & 10 \\
\hline $52-54$ & 26 & 12 & 14 \\
\hline $55-56$ & 26 & 18 & 8 \\
\hline$>56$ & 32 & 18 & 14 \\
\hline
\end{tabular}


Table 2: Distribution of observed transitions, sample size, and median unemployment duration (in days) by group and destination state

\begin{tabular}{lrrrc}
\hline \hline Age & \multicolumn{2}{c}{$40-44$} & \multicolumn{2}{c}{$45-46$} \\
Time period & Pre & Post & Pre & Post \\
\hline Column proportion & & & & \\
Recall & 0.10 & 0.07 & 0.09 & 0.06 \\
Low-wage full time & 0.13 & 0.11 & 0.12 & 0.12 \\
Other full time & 0.38 & 0.42 & 0.38 & 0.40 \\
Subsidized self-employment & 0.15 & 0.16 & 0.15 & 0.15 \\
Unknown and other & 0.16 & 0.19 & 0.17 & 0.22 \\
$\quad$ - Part-time & 0.02 & 0.01 & 0.02 & 0.01 \\
$\quad$ - Long training & 0.03 & 0.05 & 0.04 & 0.05 \\
$\quad$ - Secondary labour market & 0.01 & 0.004 & 0.01 & 0.01 \\
$\quad$ - Unknown & 0.11 & 0.13 & 0.11 & 0.15 \\
Censored & 0.07 & 0.04 & 0.09 & 0.05 \\
N of observations & 19,148 & 15,051 & 5,740 & 4,526 \\
Median duration & 174 & $122^{*}$ & 207 & $138^{*}$ \\
\hline \hline *Partly ight
\end{tabular}

*Partly right censored at the end of the year 2008 
Table 3: Sample means of variables by age group and time period (pre and post reform) period

\begin{tabular}{|c|c|c|c|c|c|}
\hline \multirow{2}{*}{$\begin{array}{l}\text { Age } \\
\text { Time period }\end{array}$} & \multirow{2}{*}{$\begin{array}{r}40-46 \\
\text { Both }\end{array}$} & \multicolumn{2}{|c|}{$40-44$} & \multicolumn{2}{|c|}{$45-46$} \\
\hline & & Pre & Post & Pre & Post \\
\hline \multicolumn{6}{|l|}{ Individual characteristics } \\
\hline Low education & 0.04 & 0.04 & 0.04 & 0.03 & 0.05 \\
\hline Vocational training or Abitur & 0.76 & 0.76 & 0.75 & 0.77 & 0.76 \\
\hline University & 0.20 & 0.20 & 0.21 & 0.20 & 0.20 \\
\hline Unskilled blue collar & 0.27 & 0.27 & 0.27 & 0.26 & 0.27 \\
\hline Skilled blue collar & 0.28 & 0.29 & 0.26 & 0.31 & 0.28 \\
\hline White collar & 0.45 & 0.43 & 0.47 & 0.43 & 0.45 \\
\hline Married & 0.63 & 0.63 & 0.59 & 0.68 & 0.65 \\
\hline Non-German & 0.12 & 0.12 & 0.13 & 0.11 & 0.13 \\
\hline \multicolumn{6}{|l|}{ During last 7 years } \\
\hline Years of employment & 6.24 & 6.17 & 6.21 & 6.40 & 6.48 \\
\hline Years of tenure at last employer & 3.58 & 3.48 & 3.54 & 3.78 & 3.87 \\
\hline Years of unemployment & 0.28 & 0.30 & 0.33 & 0.20 & 0.18 \\
\hline Number of employers & 2.55 & 2.62 & 2.58 & 2.42 & 2.36 \\
\hline Past recall & 0.14 & 0.14 & 0.14 & 0.15 & 0.14 \\
\hline \multicolumn{6}{|l|}{ Characteristics last job } \\
\hline Daily wage rate & 95.62 & 92.71 & 98.69 & 94.18 & 99.55 \\
\hline Manufacturing & 0.36 & 0.38 & 0.33 & 0.39 & 0.36 \\
\hline Agriculture, mining, energy & 0.03 & 0.03 & 0.03 & 0.03 & 0.03 \\
\hline Retail sector & 0.20 & 0.19 & 0.22 & 0.19 & 0.20 \\
\hline Hotels and restaurants & 0.02 & 0.01 & 0.02 & 0.01 & 0.02 \\
\hline Transport sector & 0.09 & 0.08 & 0.10 & 0.09 & 0.10 \\
\hline Economic and financial services & 0.17 & 0.16 & 0.18 & 0.16 & 0.17 \\
\hline Public services & 0.11 & 0.12 & 0.11 & 0.12 & 0.11 \\
\hline Temporary agency sector & 0.02 & 0.02 & 0.02 & 0.02 & 0.02 \\
\hline Firm size up to 50 & 0.52 & 0.54 & 0.51 & 0.53 & 0.50 \\
\hline Firm size 51-100 & 0.17 & 0.17 & 0.16 & 0.17 & 0.16 \\
\hline Firm size $101-250$ & 0.14 & 0.13 & 0.14 & 0.13 & 0.13 \\
\hline Firm size 251 and more & 0.18 & 0.16 & 0.19 & 0.16 & 0.20 \\
\hline \multicolumn{6}{|l|}{ Federal state } \\
\hline Nordrhein-Westfalen & 0.27 & 0.27 & 0.27 & 0.26 & 0.26 \\
\hline Schleswig-Holstein/Hamburg & 0.06 & 0.06 & 0.06 & 0.06 & 0.05 \\
\hline Niedersachsen/Bremen & 0.11 & 0.11 & 0.11 & 0.10 & 0.11 \\
\hline Hessen & 0.08 & 0.08 & 0.08 & 0.08 & 0.08 \\
\hline Rheinland-Pfalz/Saarland & 0.06 & 0.06 & 0.06 & 0.06 & 0.07 \\
\hline Baden-Württemberg & 0.13 & 0.13 & 0.13 & 0.12 & 0.13 \\
\hline Bayern & 0.15 & 0.15 & 0.15 & 0.16 & 0.16 \\
\hline Brandenburg/Berlin & 0.06 & 0.07 & 0.06 & 0.06 & 0.06 \\
\hline Mecklenburg-Vorpommern & 0.02 & 0.02 & 0.02 & 0.02 & 0.02 \\
\hline Sachsen & 0.04 & 0.04 & 0.04 & 0.04 & 0.04 \\
\hline Sachsen-Anhalt & 0.03 & 0.03 & 0.02 & 0.03 & 0.03 \\
\hline$N$ of observations & 44465 & 19148 & 15051 & 5740 & 4526 \\
\hline
\end{tabular}


Table 4: Sample means of variables by destination state

\begin{tabular}{|c|c|c|c|c|c|}
\hline Destination & $\overline{\mathrm{R}}$ & LWJ & NLWJ & SE & $\mathrm{UO}$ \\
\hline \multicolumn{6}{|l|}{ Individual characteristics } \\
\hline Low education & 0.06 & 0.05 & 0.02 & 0.02 & 0.06 \\
\hline Vocational training or Abitur & 0.85 & 0.90 & 0.74 & 0.65 & 0.73 \\
\hline University & 0.10 & 0.05 & 0.24 & 0.33 & 0.21 \\
\hline Unskilled blue collar & 0.35 & 0.46 & 0.21 & 0.12 & 0.30 \\
\hline Skilled blue collar & 0.47 & 0.35 & 0.28 & 0.19 & 0.24 \\
\hline White collar & 0.18 & 0.19 & 0.51 & 0.69 & 0.45 \\
\hline Married & 0.66 & 0.60 & 0.66 & 0.65 & 0.58 \\
\hline Non-German & 0.13 & 0.13 & 0.10 & 0.11 & 0.14 \\
\hline \multicolumn{6}{|l|}{ During last 7 years } \\
\hline Years of employment & 6.15 & 6.20 & 6.34 & 6.24 & 6.16 \\
\hline Years of tenure at last employer & 4.20 & 3.53 & 3.19 & 3.70 & 3.90 \\
\hline Years of unemployment & 0.39 & 0.36 & 0.24 & 0.22 & 0.27 \\
\hline Number of employers & 2.23 & 2.70 & 2.77 & 2.43 & 2.37 \\
\hline Past recall & 0.34 & 0.14 & 0.10 & 0.11 & 0.17 \\
\hline Past labour market program & 0.17 & 0.24 & 0.21 & 0.18 & 0.20 \\
\hline \multicolumn{6}{|l|}{ Characteristics last job } \\
\hline Daily wage rate & 79.03 & 75.54 & 101.06 & 112.76 & 94.93 \\
\hline Manufacturing & 0.36 & 0.41 & 0.37 & 0.28 & 0.36 \\
\hline Agriculture, mining, energy & 0.13 & 0.02 & 0.02 & 0.01 & 0.02 \\
\hline Retail sector & 0.14 & 0.20 & 0.21 & 0.23 & 0.18 \\
\hline Hotels and restaurants & 0.03 & 0.02 & 0.02 & 0.02 & 0.02 \\
\hline Transport sector & 0.12 & 0.13 & 0.09 & 0.05 & 0.08 \\
\hline Economic and financial services & 0.09 & 0.10 & 0.17 & 0.27 & 0.18 \\
\hline Public services & 0.12 & 0.10 & 0.10 & 0.14 & 0.15 \\
\hline Temporary agency sector & 0.02 & 0.03 & 0.02 & 0.01 & 0.01 \\
\hline firm size up to 50 & 0.70 & 0.48 & 0.53 & 0.55 & 0.46 \\
\hline Firm size $51-100$ & 0.12 & 0.18 & 0.18 & 0.16 & 0.15 \\
\hline Firm size $101-250$ & 0.08 & 0.16 & 0.14 & 0.12 & 0.15 \\
\hline \multirow{2}{*}{\multicolumn{6}{|c|}{ Federal state }} \\
\hline & & & & & \\
\hline Nordrhein-Westfalen & 0.20 & 0.25 & 0.27 & 0.26 & 0.28 \\
\hline Schleswig-Holstein/Hamburg & 0.05 & 0.05 & 0.06 & 0.05 & 0.06 \\
\hline Niedersachsen/Bremen & 0.13 & 0.10 & 0.11 & 0.10 & 0.11 \\
\hline Hessen & 0.06 & 0.07 & 0.08 & 0.09 & 0.08 \\
\hline Rheinland-Pfalz/Saarland & 0.06 & 0.06 & 0.07 & 0.06 & 0.06 \\
\hline Baden-Württemberg & 0.07 & 0.11 & 0.14 & 0.13 & 0.13 \\
\hline Bayern & 0.21 & 0.13 & 0.15 & 0.16 & 0.15 \\
\hline Brandenburg/Berlin & 0.06 & 0.08 & 0.05 & 0.07 & 0.06 \\
\hline Mecklenburg-Vorpommern & 0.04 & 0.03 & 0.01 & 0.02 & 0.01 \\
\hline Sachsen & 0.06 & 0.07 & 0.03 & 0.04 & 0.03 \\
\hline Sachsen-Anhalt & 0.05 & 0.05 & 0.02 & 0.02 & 0.02 \\
\hline$N$ of observations & 3849 & 5441 & 17527 & 6923 & 8075 \\
\hline
\end{tabular}

Note: $\mathrm{R}=$ Recall, $\mathrm{L \overline {WJ } = \text { Low-wage job, NLWJ = Non-low-wage job, SE = Self-employment, UO }}=$ Unknown or other 
Figure 1: Comparison of the partial covariate effect of pre unemployment salary estimated by MMPHM (bold black line), Cox (bold grey line) and CGE with two different copulas (solid lines with decreasing darkness represents $\tau=.0,0.1, \ldots, 0.9)$.

(a) Frank Copula

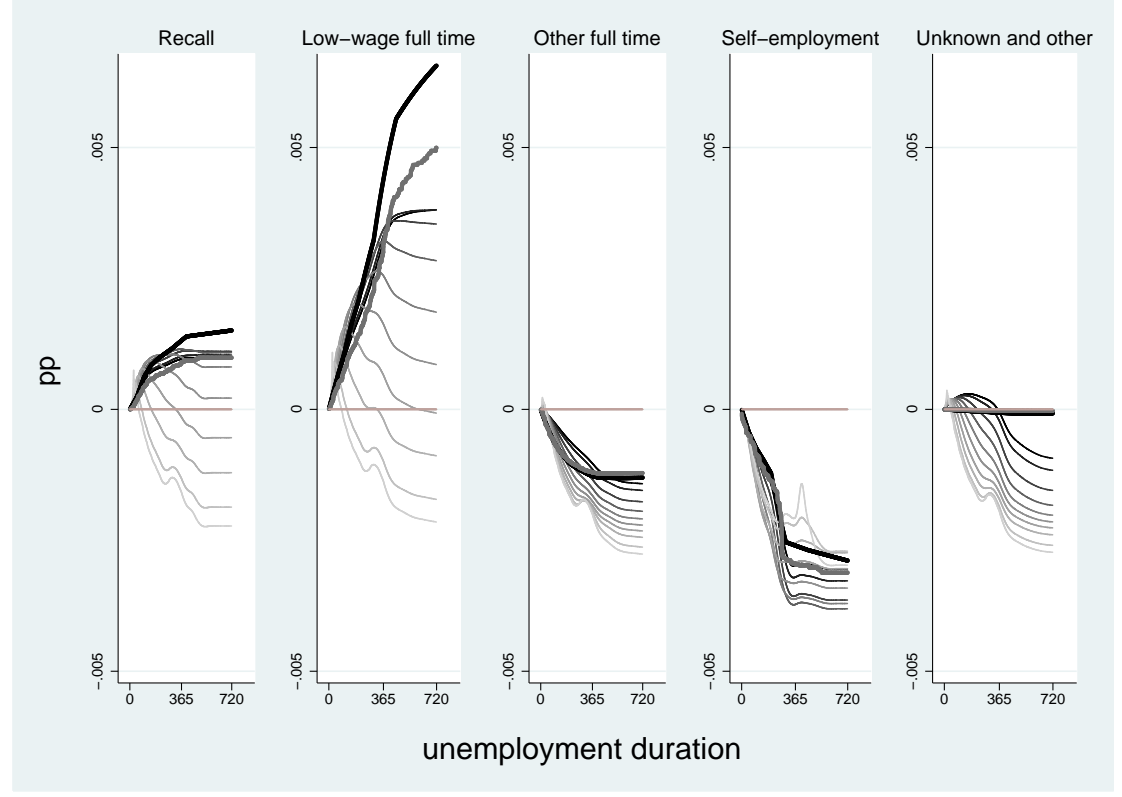

(b) Clayton Copula

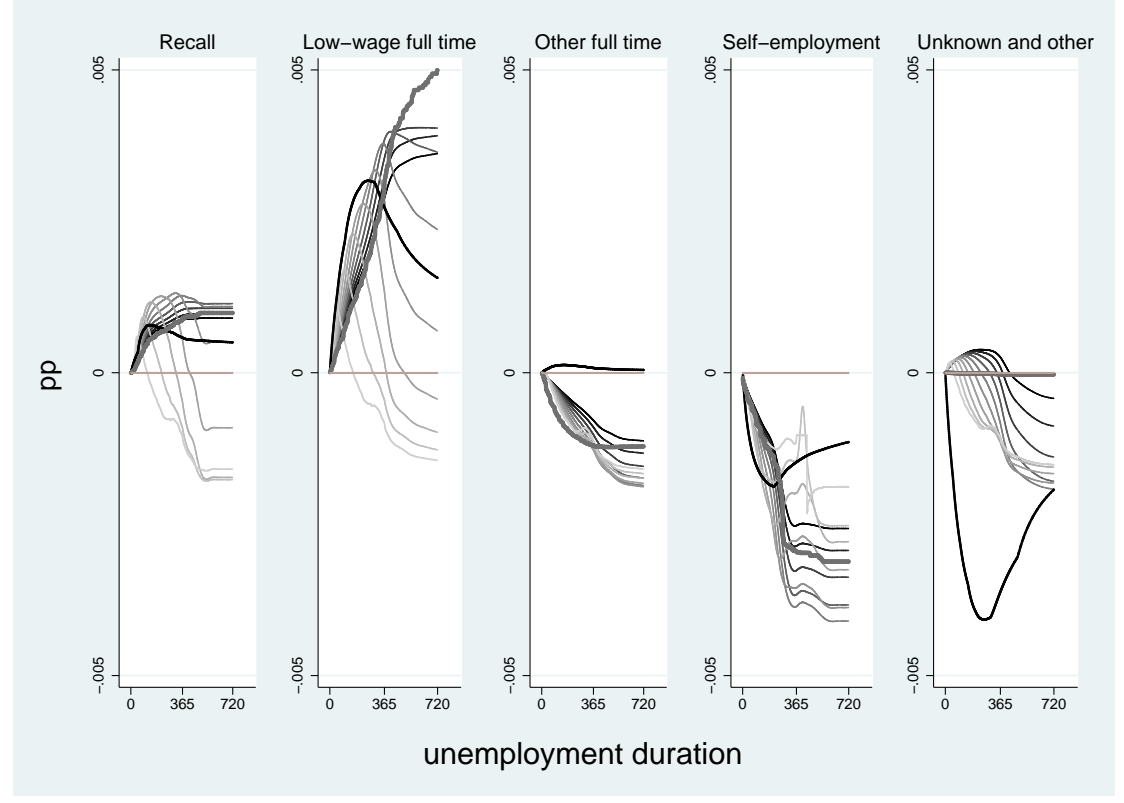


Figure 2: Estimates for the DiD reform effect obtained by CGE with Frank copula for different $\tau$ (solid lines with decreasing darkness represents $\tau=.0,0.1, \ldots, 0.9$ ).

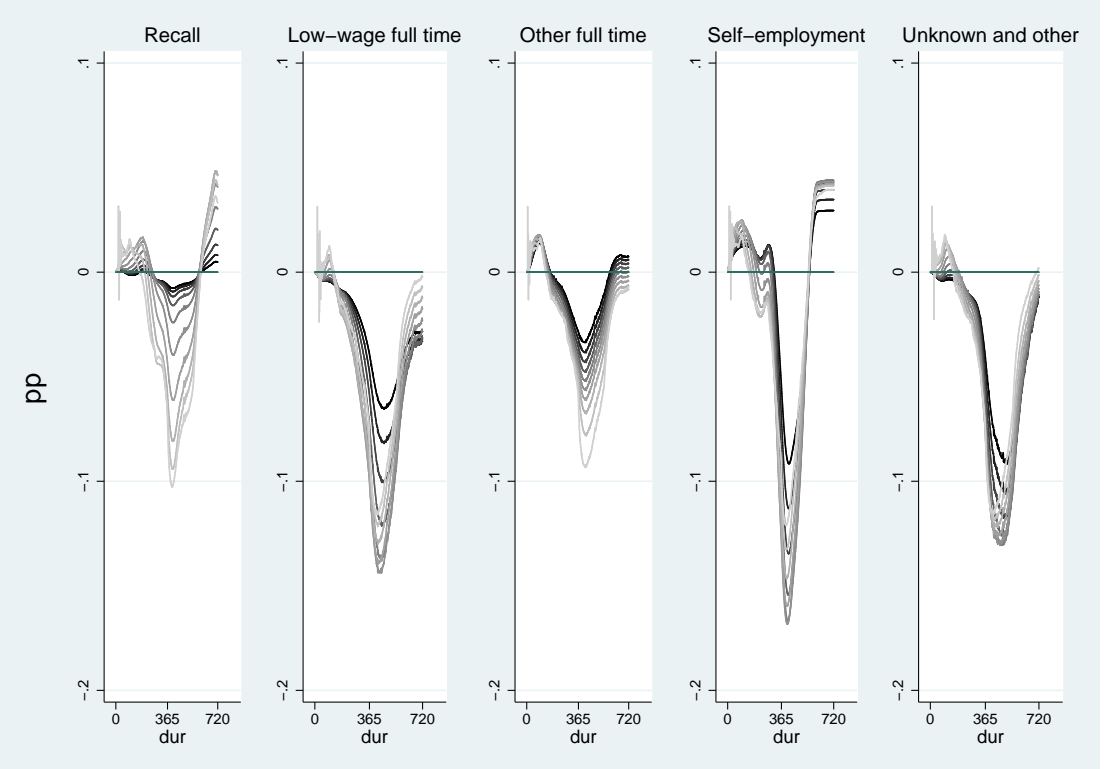


Figure 3: DiD estimates from the CGE with Frank copula (solid line) with 95\% bootstrap confidence interval (dashed line).

(a) $\tau=0$

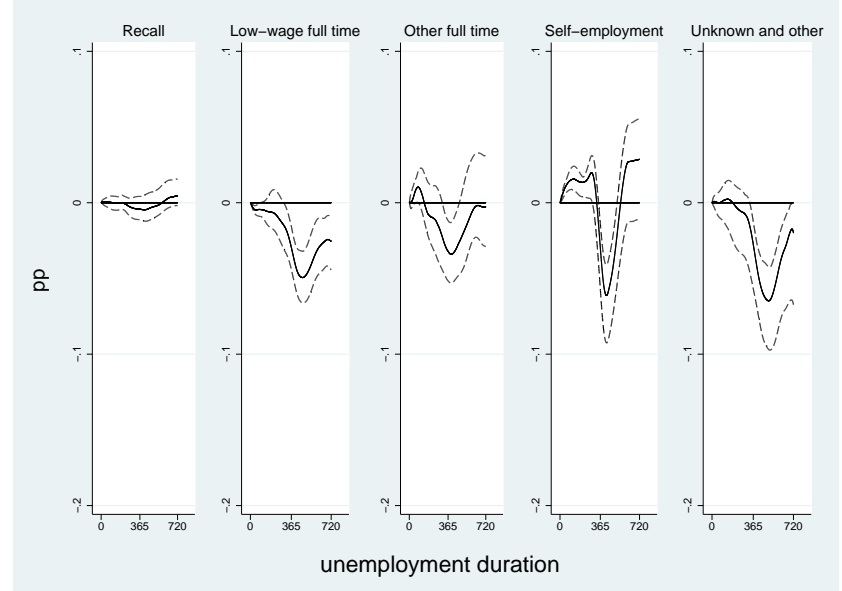

(b) $\tau=0.5$

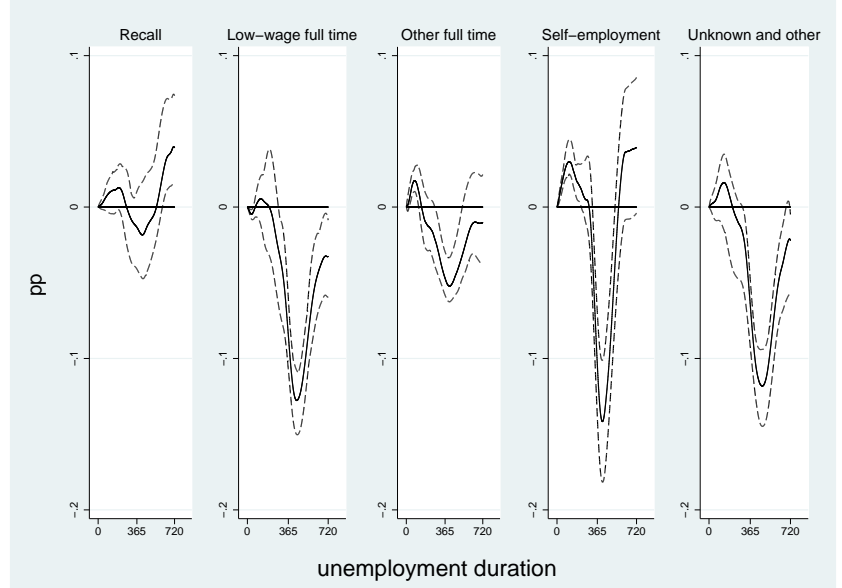

(c) $\tau=0.9$

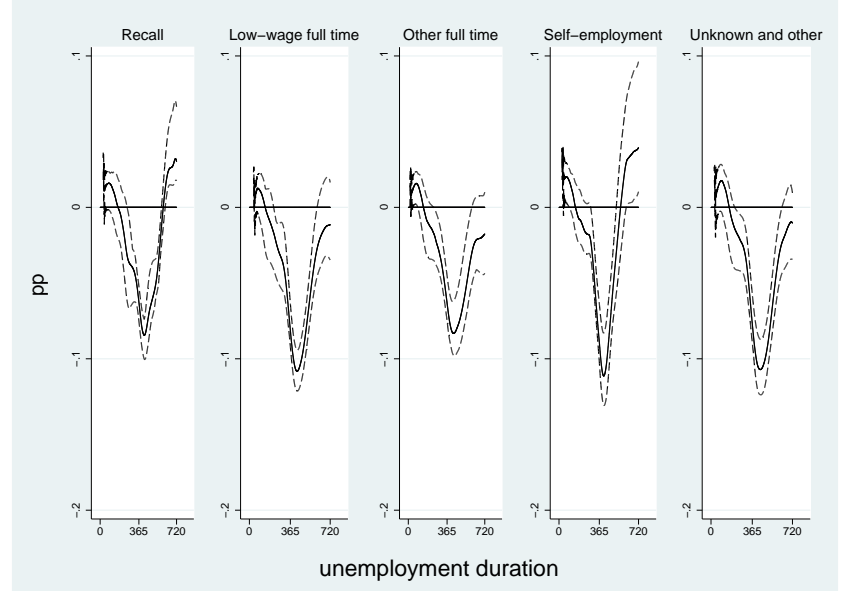


Figure 4: Estimated DiD reform effects: comparison of point estimates.

(a) CGE with Frank copula ( $\boldsymbol{\tau}$ estimated by MMPHM: $\tau_{00}=0.00, \tau_{01}=0.03, \tau_{10}=0.01$, $\tau_{11}=0.03$, solid line) and MMPHM (dashed line)

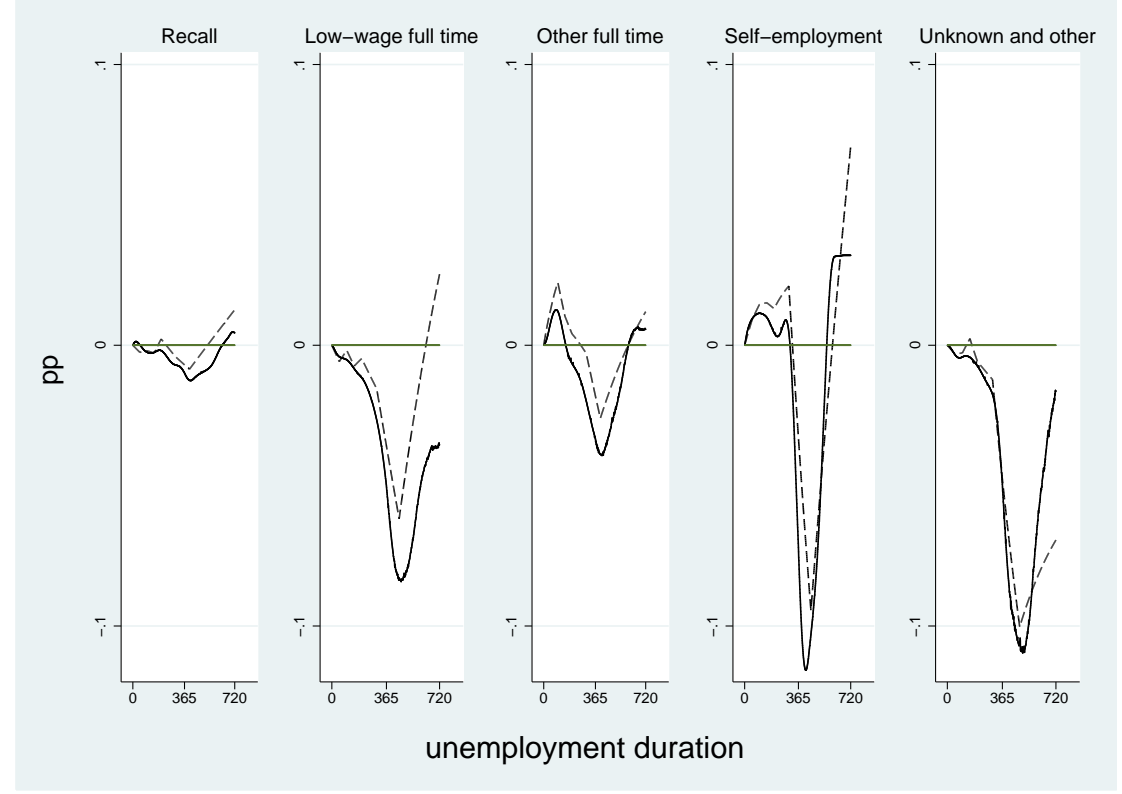

(b) CGE with Frank copula ( $\boldsymbol{\tau}=0$, solid line) and Cox model (dashed line)

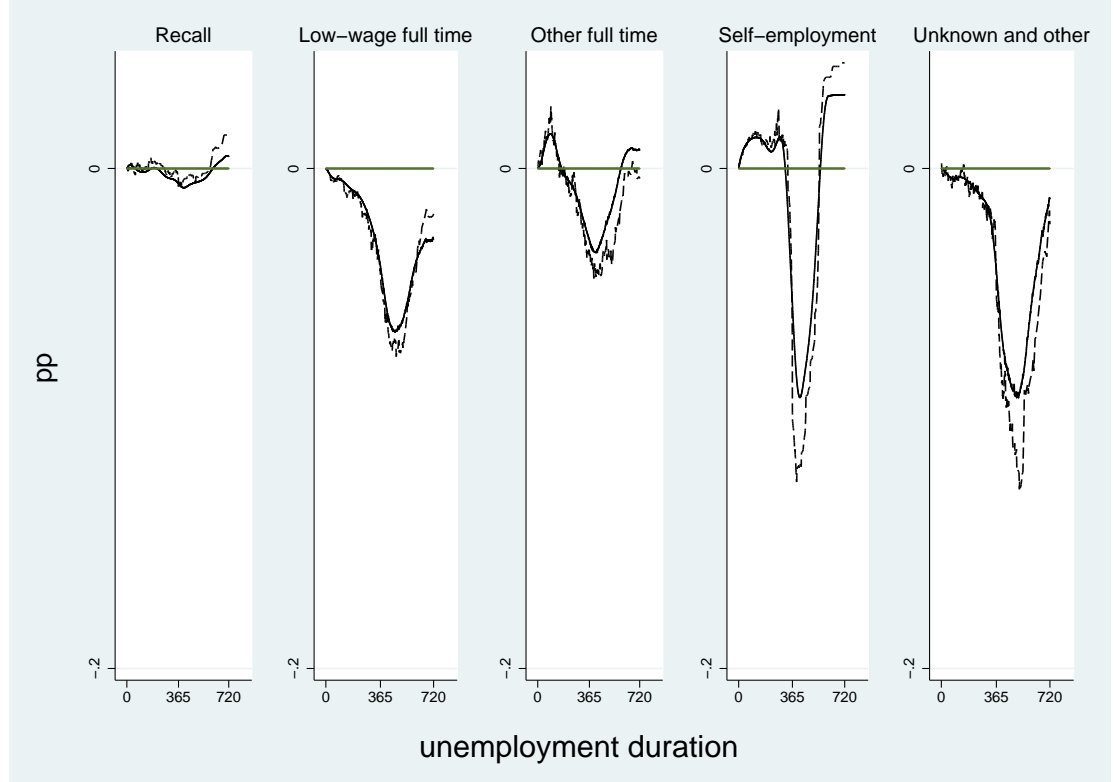


Figure 5: Estimated DiD reform effects (solid line) with 95\% bootstrap Confidence intervals (dashed line).

(a) CGE with Frank copula

$(\boldsymbol{\tau}$ estimated by MMPHM:

$\left.\tau_{00}=0.00, \tau_{01}=0.03, \tau_{10}=0.01, \tau_{11}=0.03\right)$

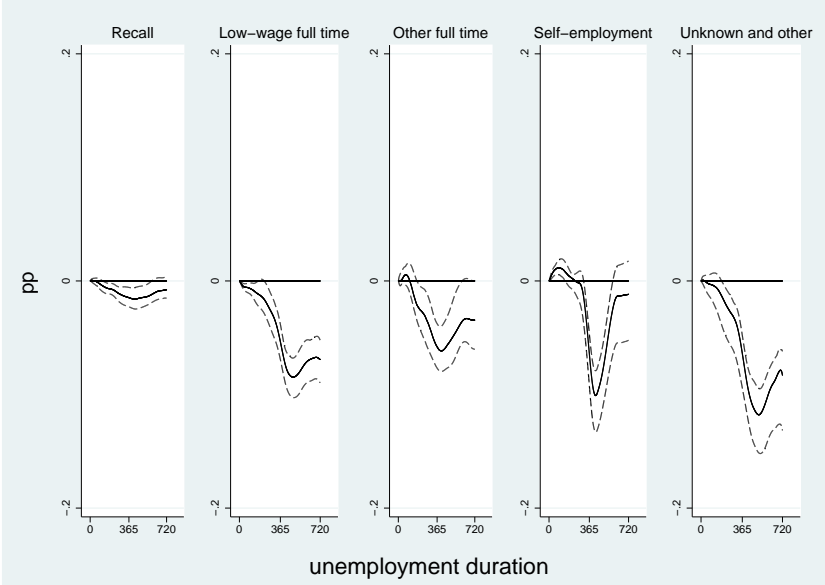

(c) MMPHM with given $\tau$

$(\boldsymbol{\tau}$ estimated by MMPHM:

$\left.\tau_{00}=0.00, \tau_{01}=0.03, \tau_{10}=0.01, \tau_{11}=0.03\right)$

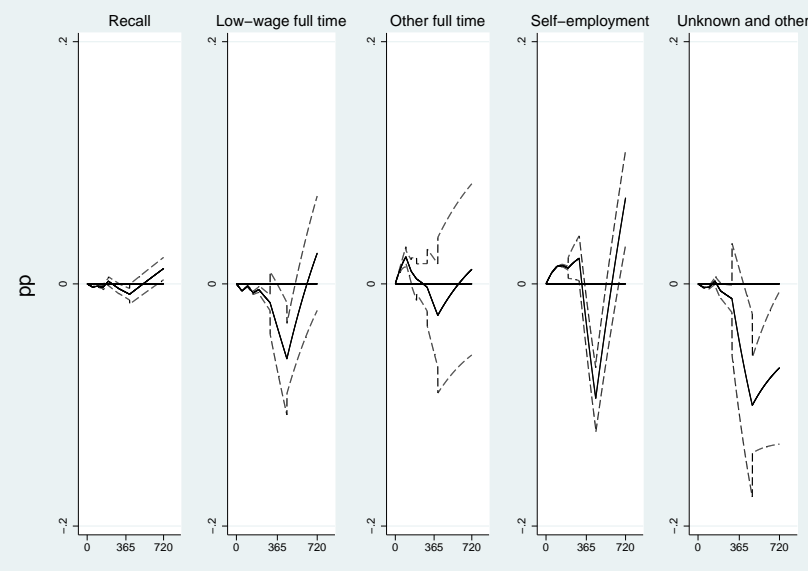

(b) MMPHM with unknown $\boldsymbol{\tau}$

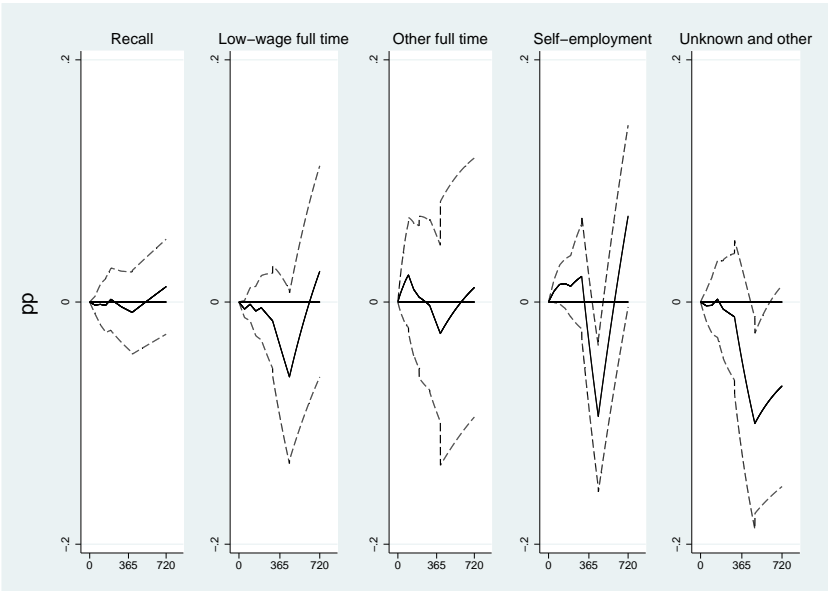

(d) Cox

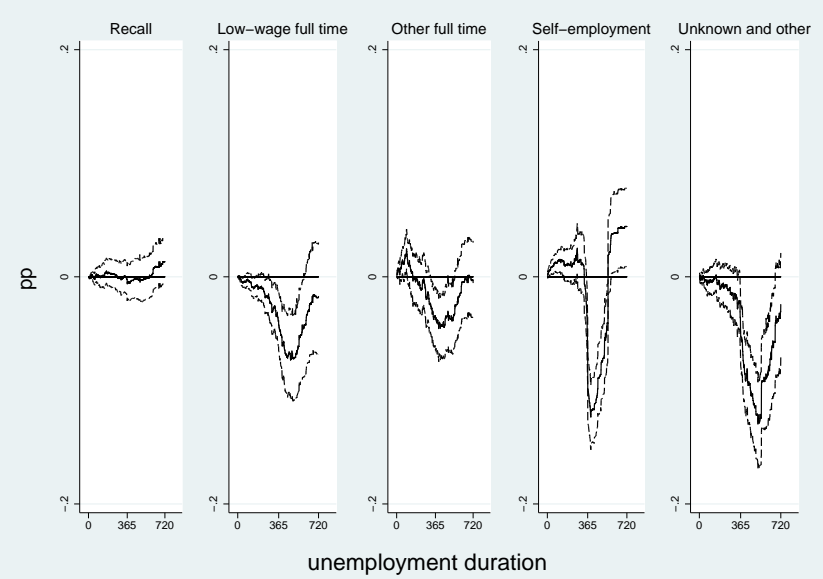


Figure 6: Comparison of estimated DiD reform effects: Frank vs. Clayton copula.

(a) MMPHM: Frank Copula (solid line) and Clatyon Copula (dashed line)

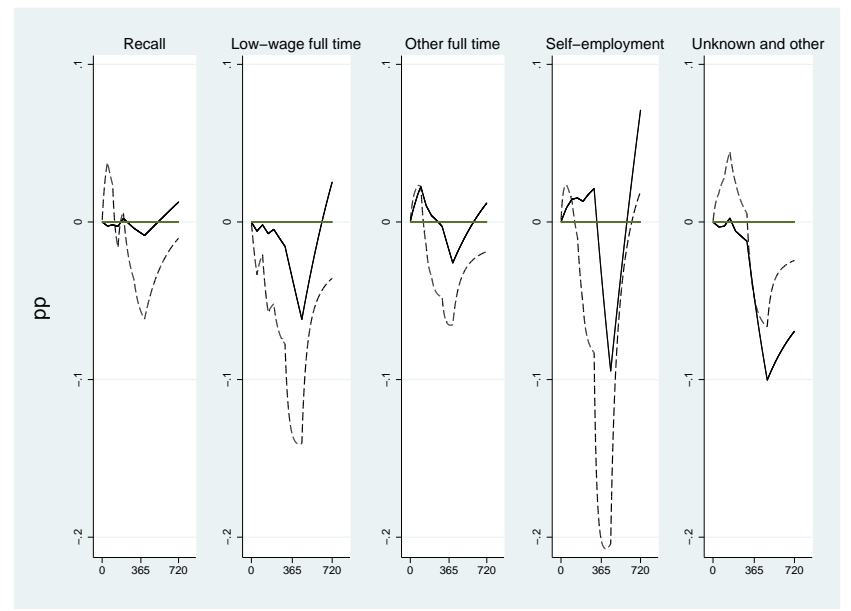

(b) CGE $\left(\boldsymbol{\tau}\right.$ by MMPHM): Frank copula $\left(\tau_{00}=0.00, \tau_{01}=0.03, \tau_{10}=0.01, \tau_{11}=0.03\right.$, solid line) and Clayton Copula $\left(\tau_{00}=.46, \tau_{01}=.40, \tau_{10}=.51\right.$, and $\tau_{11}=.44$, dashed line $)$

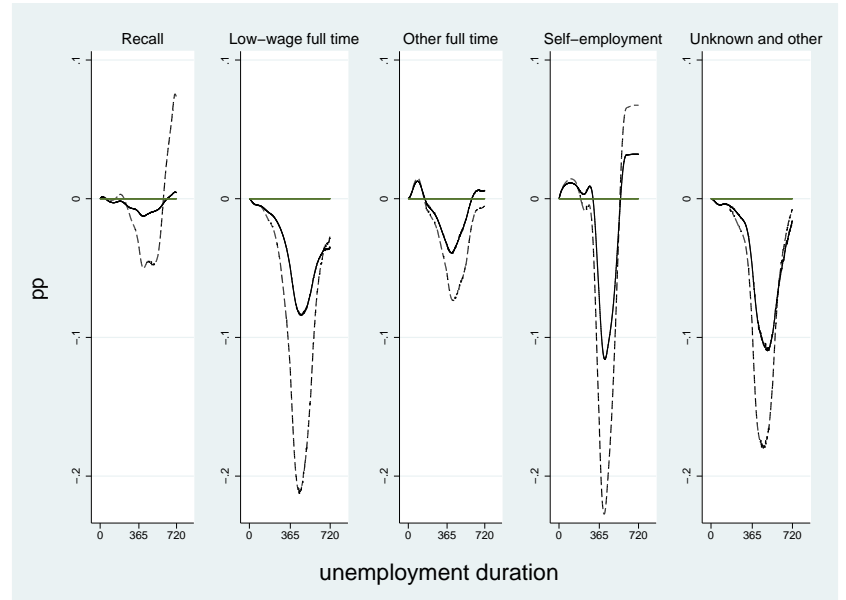

(c) CGE ( $\boldsymbol{\tau}$ by MMPHM with Clayton copula: $\tau_{00}=.46, \tau_{01}=.40, \tau_{10}=.51$, and $\tau_{11}=.44$, solid line) and MMPH (dashed line) using Clayton copula

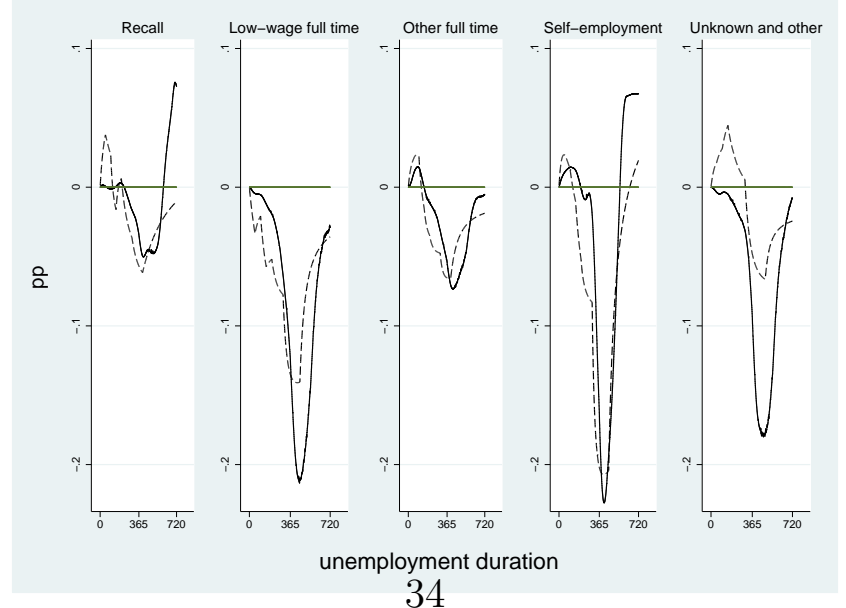

